\title{
Suicide and political regime in New South Wales and Australia during the 20th century
}

\author{
A Page, S Morrell, R Taylor
}

J Epidemiol Community Health 2002;56:766-772

\begin{abstract}
Study objective: Australia has had a two party parliamentary political system for most of the period since its Federation in 1901, dominated either by a social democratic (Labor) or a conservative ideological perspective. This paper investigates whether such political differences at Federal and State levels have influenced suicide rates in the state of New South Wales (NSW) for the period 1901-1998. Design: Federal government type, NSW State government type, and combinations of both Federal and NSW State government type were examined. Poisson regression models were stratified by sex and controlled for the effects of age, annual change in gross domestic product, sedative availability, drought, and both world wars.

Results: When both Federal and NSW State governments were conservative the relative risk of suicide for NSW men was 1.17 ( $p<0.001)$ and for women $1.40(p<0.001)$ compared with both governments being Labor (1.00). A statistically significant linear trend $(p<0.001)$ in suicide risk was evident across the continuum of Federal/State government combinations, from both Labor (lowest), to mixed (intermediate), to both conservative (highest).

Conclusion: Significantly higher suicide risk was associated with conservative government tenures compared with social democratic incumbents. Results are discussed in terms of the differences underpinning conservative and social democratic government programme ideology, and their relevance to Durkheim's theories of suicide, social regulation, and integration.
\end{abstract}

See end of article for authors' affiliations

Correspondence to: Professor R Taylor, School of Public Health, Edward Ford Building, A27, The University of Sydney, NSW, 2006, Australia: richardt@pub.health.usyd. edu.au

Accepted for publication 26 March 2002
M any suicide studies have noted the influence of wider socioeconomic and environmental factors on population suicide rates, beginning with Durkheim's 19th century study of suicide in Europe. ${ }^{1}$ Such factors include unemployment and low socioeconomic status, ${ }^{2-4}$ changes in economic activity, ${ }^{56}$ and labour force characteristics. ${ }^{7}$ Factors pertaining to access to means of suicide, for example prescription pharmaceuticals (sedatives), ${ }^{8}$ coal gas containing carbon monoxide, ${ }^{9}{ }^{10}$ and firearms ${ }^{11}{ }^{12}$ have been shown to be associated with changes in suicide rates. Also of relevance in terms of contextual determinants of suicide and interactions with other social and economic factors are climatological variables such as seasonality, ${ }^{13-15}$ precipitation and solar exposure, ${ }^{16}$ temperature and sunlight duration. ${ }^{17-19}$ More widely, the impact of economic, political, and environmental variables on general health and major cause mortality has been documented, ${ }^{20-25}$ and politically conservative, free market regimes have been shown to be associated with higher measures of deprivation, ${ }^{26}{ }^{27}$ lower birth weight and higher infant mortality, ${ }^{28}$ and lower life expectancy. ${ }^{29}$ While a number of different studies have investigated associations between attempted suicide and political affiliation or the effects of elections, ${ }^{30-32}$ there are few studies specifically investigating the influence of political regimes on suicide. ${ }^{33-37}$

In Australia and other Western countries a residue of traditional ideological difference remains between conservative versus social democratic conceptions of the role of government, which formerly was wider. Social democratic approaches have traditionally reflected at some level the interests of labour, specifically the trade union leadership, whereas conservative approaches have traditionally identified with capital, with concomitant emphasis on the free market and individual responsibility. ${ }^{38}$ Such differences have decreased over recent decades, as exemplified by the rise of "New Labour" in the United Kingdom. Of interest is whether such political differences in governmental power have been reflected in historical patterns of suicide rates. Clearly,
Durkheim's notion of anomie (less connectedness or inclusiveness) is of relevance in these conceptions of government. ${ }^{1}$

In Australia the effects of political events or regimes on suicide rates have remained largely unexplored. Accordingly, this paper investigates the association between the dominant political parties (and their combination) at Federal and State government levels and suicide mortality in New South Wales since Federation, a period spanning 1901 to 1998. The analysis adjusts for the differential pattern of suicide across age groups over time ${ }^{2}$ and for the potentially confounding variables pertaining to wider social, economic, and seasonal trends such as annual changes in gross domestic product (GDP), world war, drought, and the availability of sedatives during the 1960s, variables that, from the studies quoted above, seem to relate to suicide variability. As drought in Australia has substantial and important effects on many primary industries that do not necessarily appear in GDP changes, its association with suicide is not merely climatological but also has economic relevance.

\section{METHOD}

Data

NSW suicide mortality data for the period 1901-1998 were obtained from Australian Bureau of Statistics (ABS) year books. Population denominator data were obtained from ABS census information, with inter-censal year populations estimated using weighted interpolation. Data were categorised into five year age groups from $15-19$ years to $\geqslant 80$ years. Given the variable classification protocols over time, biases may exist in Australian suicide data, ${ }^{39}$ but it has been observed that the magnitude of such biases do not preclude the use of suicide data for aggregate or secular analyses ${ }^{40}$ Estimates of national GDP provided by Butlin ${ }^{41}$ were used to calculate the per cent annual GDP change for the period under investigation. Additional information on annual changes in GDP were obtained from the ABS for the period 1984-1998. Annual changes in 
GDP were then grouped into five categories: negative GDP change of $10 \%$ or more, $5 \%$ and up to $10 \%$ negative change, between $-5 \%$ and $5 \%$ change, between $5 \%$ and up to $10 \%$ positive change, and $10 \%$ or greater positive change. This economic variable was used to control for the year to year changes in national economic performance.

Occurrence of drought was taken from Bureau of Meteorology (BOM) data, ${ }^{42}$ based on the definition adopted by the $\mathrm{BOM}$, and coded as a categorical variable. This variable was used to control for the possible influence of extreme climatological hardship especially in the earlier periods of the 20th century where economic and social stability was more dependent on agricultural enterprise. A similar method was used for the first and second world wars. The world war variables were modelled primarily to control for the artefactual drop in male suicide rates during the second world war when servicemen were not included in mortality data, ${ }^{43}$ and for the real but unmeasured drops in suicide observed in civilian populations during both world wars. The availability of sedatives during 1960-1967 under the government subsidised Pharmaceutical Benefits Scheme, known to have affected Australian suicide rates (especially in women), ${ }^{8}$ was also included as a variable. Access to sedatives was restricted in 1967, which limited the number of tablets prescribed and the number of prescription repeats, after which decreases in suicide attributable to self poisoning were observed. ${ }^{8}$

Data on which political parties held power were obtained from Grattan ${ }^{44}$ and coded into a categorical variable as either "Conservative" or "Labor". In instances where governments changed mid-year, the party that had governed for the majority of the year was coded as the government for the whole year. Data on NSW governing parties were obtained from the NSW Parliamentary Library (1980) and coded similarly. ${ }^{45}$ Combinations of Federal and State government type on NSW suicide mortality rates were also investigated. The resultant categorical variable comprised periods where Federal and NSW State government combinations were "Conservative/Conservative", "Conservative/Labor", "Labor/Conservative", or "Labor/Labor". As risk estimates in the two mixed categories were similar, these were aggregated for trend analysis.

\section{Analysis}

Data were analysed with regression models using a log link function with a Poisson error distribution. The following general model was defined and examined:

$$
\begin{aligned}
& \ln \left(\frac{n_{i}}{p_{i}}\right)=\beta_{1} \text { age }+\beta_{2} \Delta G D P+\beta_{3} \text { drought } \\
& +\beta_{4} W W 1+\beta_{5} W W 2+\beta_{6} \text { sedatives }+\beta_{7} \text { govt }+k
\end{aligned}
$$

where $n_{i}$ refers to the number of suicides for a given year, $p_{i}$ the corresponding denominator population, $\beta_{1} \ldots \beta_{7}$ the relevant regression coefficients or estimates, with $k$ as the constant. Age refers to five year age group, $\triangle G D P$ refers to percentage annual change in GDP, drought refers to drought occurrence as defined by the BOM, $W W 1$ and $W W 2$ refer to the first and second world wars respectively, and sedatives refers to increased sedative availability. The variable govt refers to the type of Federal or NSW State government, or to the various possible combinations of Federal and NSW State governments over the study period, as defined above. All variables are categorical. Separate models of Federal, State, and combinations of Federal and State governments were examined. Risk estimates were generated for each variable adjusting for age only to compare with the above models. The models were validated through investigation of sub-periods and sub-groups on a post hoc basis. This was to examine the possibility that any association found with a governmental regime was attributable to the influence of, for example, the second world war artefact in men (lower suicide rates during a Labor government) or the sedative epidemic in the 1960s in women (higher suicide rates during a conservative government). Young, middle, and older age groups were also analysed separately, as were earlier and later periods of the century. Time series analysis was also conducted in relation to the identified socioeconomic and historical variables, defined as interventions where appropriate. Statistical analyses were conducted using SAS statistical software. $^{46}$

\section{RESULTS}

Tables 1, 2, and 3 show the extent of association of the type of Federal or NSW State government with NSW suicide mortality data for men and women adjusting for age only, and adjusting for age, annual changes in GDP, sedative availability, world war, and drought. As can be observed from table l, after adjusting for all variables a significant positive association is evident between Federal conservative governments and increased suicide risk in NSW for men $(R R=1.07, p<0.01)$, with a stronger association found in women $(R R=1.22$, $\mathrm{p}<0.001)$. The effects in both men and women were similar after controlling only for age. The effects of conservative NSW State governments (table 2 ) were also positively associated with increased risk of male suicide $(R R=1.09, p<0.001)$ and female suicide $(R R=1.17, p<0.001)$ in NSW, with the risk estimates being slightly lower for women than in the case of Federal conservative governments. And as was the case for the Federal analysis, these effects were similar to those found after adjusting for age only. The magnitude and statistical significance of the association between government type and suicide did not change after adjusting simultaneously for NSW State and Federal government type.

The effect of combinations of Federal and NSW State government on suicide risk is shown in table 3, with Labor in both Federal and NSW State governments as the referent group. As can be observed, when Federal and NSW State governments are both conservative, suicide risk is greatest. The relative risk for male suicide under a conservative Federal and State government was $1.17(\mathrm{p}<0.001)$. For women this estimate was $1.40(\mathrm{p}<0.001)$. Similarly significant results are evident when a NSW State Labor government coexists with a Conservative Federal government and vice versa, but the effect size is not as marked, with relative risks ranging from 1.07 $(p<0.05)$ to $1.09(p<0.05)$ for men, and 1.09 to 1.16 $(\mathrm{p}<0.001)$ for women.

Confounding variables were found also to be significantly associated with suicide. For men, relative risks associated with annual changes in GDP suggest an increased suicide risk with dramatic decreases in GDP, as shown by significantly higher relative risks for negative annual GDP changes of $10 \%$ or greater for Federal, State, and combined government models. For women, negative annual changes in GDP were not associated with increased suicide risk, but positive changes of greater than $5 \%$ were associated with increased female suicide risk for each model. Periods of drought were also associated with increased suicide risk, particularly in women. In both the Federal and combined models, a decreased suicide risk is also evident for women during the first world war period. Significantly lower suicide risks for both men and women were evident during the second world war.

Figure 1 shows the risk estimates for combinations of Federal and State governments, with discordant combinations (that is, conservative/non-conservative) collapsed into a single category as the relative risk estimates for the converse of these combinations were similar (see table 3). Figure 1 demonstrates a statistically significant increasing linear trend for both men and women when government combination is defined as an ordinal variable, with risk increasing monotonically from non-conservative to conservative government 
Table 1 Influence of type of Federal government and other factors on suicide in NSW (1901-1998)

\begin{tabular}{|c|c|c|c|c|c|c|c|c|}
\hline & \multicolumn{4}{|l|}{ Men } & \multicolumn{4}{|l|}{ Women } \\
\hline & $\begin{array}{l}\text { Number of } \\
\text { suicides }\end{array}$ & $\begin{array}{l}\text { Rate/ } \\
100000 \\
\text { adjusted for } \\
\text { age only }\end{array}$ & $\begin{array}{l}\text { RR adjusted } \\
\text { for age only }\end{array}$ & $\begin{array}{l}\text { RR adjusted } \\
\text { for age and } \\
\text { all other } \\
\text { variables }\end{array}$ & $\begin{array}{l}\text { Number of } \\
\text { suicides }\end{array}$ & $\begin{array}{l}\text { Rate/ } \\
100000 \\
\text { adjusted for } \\
\text { age only }\end{array}$ & $\begin{array}{l}\text { RR adjusted } \\
\text { for age only }\end{array}$ & $\begin{array}{l}\text { RR adjusted } \\
\text { for age and } \\
\text { all other } \\
\text { variables }\end{array}$ \\
\hline \multicolumn{9}{|l|}{ Federal government } \\
\hline Labor $†$ & 13667 & 23.85 & 1.00 & 1.00 & 4007 & 7.17 & 1.00 & 1.00 \\
\hline Conservative & 19314 & 25.76 & $1.08 * * *$ & $1.07 * *$ & 7083 & 9.03 & $1.26 * * *$ & $1.22 * * *$ \\
\hline \multicolumn{9}{|l|}{$\%$ Annual change in GDP } \\
\hline Minus $10 \%$ & 529 & 14.27 & $1.44^{* * *}$ & $1.50 * * *$ & 106 & 34.47 & 1.01 & 1.24 \\
\hline Minus 5-9\% & 594 & 11.10 & $1.12^{*}$ & 1.13 & 142 & 26.81 & 0.93 & 1.03 \\
\hline Minus $4 \%$ to plus $4 \% \dagger$ & 5118 & 9.91 & 1.00 & 1.00 & 1475 & 23.94 & 1.00 & 1.00 \\
\hline Plus 5-9\% & 10344 & 10.60 & 1.07 & 1.03 & 3429 & 25.62 & $1.17 * * *$ & 1.08 \\
\hline Plus $10 \%$ & 12568 & 9.91 & 1.00 & 0.96 & 4758 & 23.94 & $1.21 * * *$ & $1.22 * * *$ \\
\hline \multicolumn{9}{|l|}{ Drought } \\
\hline No drought $†$ & 20639 & 24.17 & 1.00 & 1.00 & 6610 & 7.81 & 1.00 & 1.00 \\
\hline Drought & 12342 & 24.17 & 1.00 & 1.07 * & 4480 & 8.98 & $1.15^{* * *}$ & $1.19 * * *$ \\
\hline \multicolumn{9}{|l|}{ First world war } \\
\hline No wart & 32107 & 24.45 & 1.00 & 1.00 & 10871 & 8.38 & 1.00 & 1.00 \\
\hline War & 874 & 26.41 & 1.08 & 1.07 & 219 & 7.29 & 0.87 & $0.82 *$ \\
\hline \multicolumn{9}{|l|}{ Second world war } \\
\hline No wart & 31827 & 24.80 & 1.00 & 1.00 & 10654 & 8.42 & 1.00 & 1.00 \\
\hline War & 1154 & 17.61 & $0.71 * * *$ & $0.70 * * *$ & 436 & 6.73 & 0.80 & 0.81 * * \\
\hline \multicolumn{9}{|l|}{ Sedative epidemic } \\
\hline No sedatives $†$ & 29720 & 24.17 & 1.00 & 1.00 & 9367 & 7.73 & 1.00 & 1.00 \\
\hline Sedatives & 3261 & 28.04 & $1.16 * * *$ & $1.08 *$ & 1723 & 13.61 & $1.76 * * *$ & $1.55^{* \star *}$ \\
\hline
\end{tabular}

Table 2 Influence of type of State government and other factors on suicide in NSW (1901-1998)

\begin{tabular}{|c|c|c|c|c|c|c|c|c|}
\hline & \multicolumn{4}{|l|}{ Men } & \multicolumn{4}{|l|}{ Women } \\
\hline & $\begin{array}{l}\text { Number of } \\
\text { suicides }\end{array}$ & $\begin{array}{l}\text { Rate/ } \\
100000 \\
\text { adjusted for } \\
\text { age only }\end{array}$ & $\begin{array}{l}\text { RR adjusted } \\
\text { for age only }\end{array}$ & $\begin{array}{l}\text { RR adjusted } \\
\text { for age and } \\
\text { all other } \\
\text { variables }\end{array}$ & $\begin{array}{l}\text { Number of } \\
\text { suicides }\end{array}$ & $\begin{array}{l}\text { Rate/ } \\
100000 \\
\text { adjusted for } \\
\text { age only }\end{array}$ & $\begin{array}{l}\text { RR adjusted } \\
\text { for age only }\end{array}$ & $\begin{array}{l}\text { RR adjusted } \\
\text { for age and } \\
\text { all other } \\
\text { variables }\end{array}$ \\
\hline \multicolumn{9}{|l|}{ State government } \\
\hline Labort & 18383 & 23.89 & 1.00 & 1.00 & 6088 & 8.06 & 1.00 & 1.00 \\
\hline Conservative & 14598 & 26.51 & $1.11^{* * *}$ & $1.09 * * *$ & 5002 & 9.59 & $1.19 * * *$ & $1.17^{* * *}$ \\
\hline \multicolumn{9}{|l|}{$\%$ Annual change in GDP } \\
\hline Minus $10 \%$ & 529 & 13.47 & $1.44 * * *$ & $1.36 * *$ & 106 & 34.47 & 1.01 & 1.00 \\
\hline Minus 5-9\% & 594 & 10.90 & $1.12 *$ & 1.10 & 142 & 26.81 & 0.93 & 0.99 \\
\hline Minus $4 \%$ to plus $4 \% \dagger$ & 5118 & 9.91 & 1.00 & 1.00 & 1475 & 23.94 & 1.00 & 1.00 \\
\hline Plus $5-9 \%$ & 10344 & 10.40 & 1.07 & 1.05 & 3429 & 25.62 & $1.17 * * *$ & $1.13^{* *}$ \\
\hline Plus $10 \%$ & 12568 & 9.61 & 1.00 & 0.97 & 4758 & 23.94 & $1.21 * * *$ & $1.24 * * *$ \\
\hline \multicolumn{9}{|l|}{ Drought } \\
\hline No drought† & 20639 & 24.17 & 1.00 & 1.00 & 6610 & 7.81 & 1.00 & 1.00 \\
\hline Drought & 12342 & 24.17 & 1.00 & 1.00 & 4480 & 8.98 & $1.15^{\star \star *}$ & 1.04 \\
\hline \multicolumn{9}{|l|}{ First world war } \\
\hline No wart & 32107 & 24.45 & 1.00 & 1.00 & 10871 & 8.38 & 1.00 & 1.00 \\
\hline War & 874 & 26.41 & 1.08 & 1.08 & 219 & 7.29 & 0.87 & 0.85 \\
\hline \multicolumn{9}{|l|}{ Second world war } \\
\hline No wart & 31827 & 24.80 & 1.00 & 1.00 & 10654 & 8.42 & 1.00 & 1.00 \\
\hline War & 1154 & 18.35 & $0.71 * * *$ & $0.74 * * *$ & 436 & 6.73 & 0.80 & 0.90 \\
\hline \multicolumn{9}{|l|}{ Sedative epidemic } \\
\hline No sedatives $†$ & 29720 & 24.17 & 1.00 & 1.00 & 9367 & 7.73 & 1.00 & 1.00 \\
\hline Sedatives & 3261 & 27.31 & $1.16 * * *$ & $1.13^{* * *}$ & 1723 & 13.61 & $1.76 * * *$ & $1.74 * * *$ \\
\hline
\end{tabular}

groupings (table 4). In the fully adjusted models, suicide risk increases an average $9 \%$ for men and $20 \%$ for women across each category.

Further subgroup analyses were undertaken for broad age groups and periods to determine if differences existed in the association between suicide and government regime. Furthermore, analyses were conducted that excluded periods with known artefactual or real impacts on suicide as an additional control for confounding. Analyses of sub-periods revealed that the increased risk of suicide associated with conservative governments differed in magnitude over the study period, with the relative risks associated with conservative governments compared with social democratic governments being higher in the post-second world war period than in the pre-second world war period. Significantly higher relative risk estimates for conservative governments remained when the analysis excluded the second world war period that is affected by the lower suicide artefact in men, coinciding with a period of Labor government. A similar analysis excluding the period of the sedative epidemic, a period that coincided with a conservative government, also resulted in significantly higher suicide risk under conservative governments.

Stratified analyses by broad age group $(15-24,25-59, \geqslant 60$ years) were conducted to examine whether the association of 


\begin{tabular}{|c|c|c|c|c|c|c|c|c|}
\hline & \multicolumn{4}{|l|}{ Men } & \multicolumn{4}{|l|}{ Women } \\
\hline & $\begin{array}{l}\text { Number } \\
\text { of suicides }\end{array}$ & $\begin{array}{l}\text { Rate/ } 100000 \\
\text { adjusted for } \\
\text { age only }\end{array}$ & $\begin{array}{l}\text { RR adjusted } \\
\text { for age only }\end{array}$ & $\begin{array}{l}\text { RR adjusted for } \\
\text { age and all } \\
\text { other variables }\end{array}$ & $\begin{array}{l}\text { Number } \\
\text { of suicides }\end{array}$ & $\begin{array}{l}\text { Rate/ } 100000 \\
\text { adjusted for } \\
\text { age only }\end{array}$ & $\begin{array}{l}\text { RR adjusted } \\
\text { for age only }\end{array}$ & $\begin{array}{l}\text { RR adjusted for } \\
\text { age and all } \\
\text { other variables }\end{array}$ \\
\hline \multicolumn{9}{|c|}{ Federal/State govt combination } \\
\hline Labor/Labor† & 7391 & 23.02 & 1.00 & 1.00 & 2121 & 7.00 & 1.00 & 1.00 \\
\hline Labor/Conservative & 6276 & 26.71 & $1.16 * * *$ & $1.09 *$ & 1886 & 7.84 & $1.12^{*}$ & 1.09 \\
\hline Conservative/Labor & 10992 & 25.78 & $1.12 * * *$ & $1.07^{*}$ & 3967 & 8.47 & $1.21^{* * *}$ & $1.16 * * *$ \\
\hline $\begin{array}{l}\text { Conservative/Conservative } \\
\% \text { Annual change in GDP }\end{array}$ & 8322 & 28.32 & $1.23^{* * *}$ & $1.17^{* * *}$ & 3116 & 10.78 & $1.54^{* * *}$ & 1.40 *** \\
\hline \multicolumn{9}{|c|}{$\%$ Annual change in GDP } \\
\hline Minus $10 \%$ & 529 & 14.27 & $1.44^{* * *}$ & $1.43^{* * *}$ & 106 & 34.47 & 1.01 & 1.16 \\
\hline Minus 5-9\% & 594 & 11.10 & $1.12^{*}$ & 1.12 & 142 & 26.81 & 0.93 & 0.98 \\
\hline Minus $4 \%$ to plus $4 \% \dagger$ & 5118 & 9.91 & 1.00 & 1.00 & 1475 & 23.94 & 1.00 & 1.00 \\
\hline Plus 5-9\% & 10344 & 10.60 & 1.07 & 1.04 & 3429 & 25.62 & $1.17^{* * *}$ & $1.10^{*}$ \\
\hline Plus $10 \%$ & 12568 & 9.91 & 1.00 & 0.97 & 4758 & 23.94 & $1.21^{* * *}$ & $1.23^{* * *}$ \\
\hline \multicolumn{9}{|l|}{ Drought } \\
\hline No drought $\dagger$ & 20639 & 24.17 & 1.00 & 1.00 & 6610 & 7.81 & 1.00 & 1.00 \\
\hline Drought & 12342 & 24.17 & 1.00 & 1.03 & 4480 & 8.98 & $1.15^{* * *}$ & $1.12^{* * *}$ \\
\hline \multicolumn{9}{|l|}{ First world war } \\
\hline No wart & 32107 & 24.45 & 1.00 & 1.00 & 10871 & 8.38 & 1.00 & 1.00 \\
\hline War & 874 & 26.41 & 1.08 & 1.07 & 219 & 7.29 & 0.87 & $0.81^{*}$ \\
\hline \multicolumn{9}{|l|}{ Second world war } \\
\hline No wart & 31827 & 24.80 & 1.00 & 1.00 & 10654 & 8.42 & 1.00 & 1.00 \\
\hline War & 1154 & 17.61 & $0.71^{* * *}$ & $0.73^{* * *}$ & 436 & 6.73 & 0.80 & $0.86^{*}$ \\
\hline \multicolumn{9}{|l|}{ Sedative epidemic } \\
\hline No sedatives $\dagger$ & 29720 & 24.17 & 1.00 & 1.00 & 9367 & 7.73 & 1.00 & 1.00 \\
\hline Sedatives & 3261 & 28.04 & $1.16^{* * *}$ & $1.09^{*}$ & 1723 & 13.61 & $1.76^{* * *}$ & $1.56^{* * *}$ \\
\hline
\end{tabular}

Table 4 The effect of Federal/State government combinations on male and female suicide risk in NSW (1901-1998)

\begin{tabular}{|c|c|c|c|c|c|c|c|c|}
\hline & \multicolumn{4}{|l|}{ Men } & \multicolumn{4}{|l|}{ Women } \\
\hline & $\begin{array}{l}\text { Number } \\
\text { of suicides }\end{array}$ & $\begin{array}{l}\text { Rate/ } 100000 \\
\text { adjusted for } \\
\text { age only }\end{array}$ & $\begin{array}{l}\text { RR adjusted } \\
\text { for age only }\end{array}$ & $\begin{array}{l}\text { RR adjusted for } \\
\text { age and other } \\
\text { variables }\end{array}$ & $\begin{array}{l}\text { Number } \\
\text { of suicides }\end{array}$ & $\begin{array}{l}\text { Rate/ } 100000 \\
\text { adjusted for } \\
\text { age only }\end{array}$ & $\begin{array}{l}\text { RR adjusted } \\
\text { for age only }\end{array}$ & $\begin{array}{l}\text { RR adjusted for } \\
\text { age and other } \\
\text { variables }\end{array}$ \\
\hline \multicolumn{9}{|c|}{ Federal/State govt combination } \\
\hline Both Labort & 7391 & 23.02 & 1.00 & 1.00 & 2121 & 7.00 & 1.00 & 1.00 \\
\hline Mixed & 17268 & 26.01 & $1.13^{* * *}$ & $1.08 * *$ & 5853 & 8.26 & $1.18^{* * *}$ & $1.14^{* * *}$ \\
\hline Both conservative & 8322 & 28.32 & $1.23^{* * *}$ & $1.17^{* * *}$ & 3116 & 10.78 & $1.54^{* * *}$ & $1.40 * * *$ \\
\hline Linear trend & & & $p<0.001$ & $p<0.001$ & & & $p<0.001$ & $p<0.001$ \\
\hline
\end{tabular}

conservative governments with higher rates of suicide differed by age. These analyses revealed the increased relative risk estimates of suicide associated with conservative governments to occur in both middle and older age groups, men and women,

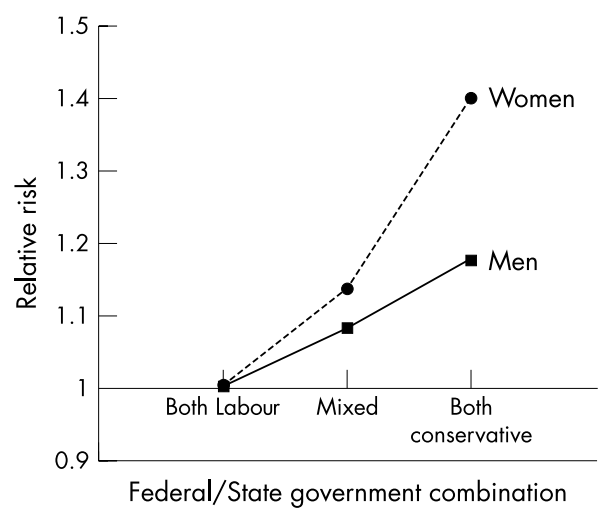

Figure 1 Effect of Federal/State government combinations on male and female suicide risk in NSW, 1901-1998. Adjusted for age, annual change in GDP $(\%)$, drought, first world war, second world war, and sedative epidemic. while the association was lower and not statistically significant in the younger age group.

The positive association between drought occurrence and suicide remained significant for both men and women after conducting interrupted time series analysis. Results of time series analysis also indicated an association with the major decrease in male suicide during the second world war period, and the increase in female suicide during the 1960s attributable to sedative availability, with the respective suicide risk estimates being in the appropriate direction (that is, negative for the second world war decrease in male suicide, and positive for the increase in women during the sedative epidemic). However, these latter estimates were not statistically significant. Interrupted time series analysis indicated a positive relation between suicide and conservative government combinations, but this was not statistically significant.

\section{DISCUSSION}

The results of Poisson regression modelling of suicide in NSW controlled for the effects of age, annual changes in GDP, world war, drought, and sedative availability showed significant positive associations between conservative governments and higher suicide rates for the period 1901-1998. Of particular note are the higher relative risk estimates for NSW women 
during conservative governments, which were highest when both Federal and NSW State governments were conservative. Aside from the sedative epidemic of 1961-1967, very few social or economic factors have hitherto been found to be associated with female suicide variability in Australia. A combination of a conservative Federal government with a Labor State government, and vice versa, also was significantly associated with increased suicide risk in NSW women, but the association was not as great as when both governments were conservative. Consequently a significant increasing monotonic "dose-response" trend was evident from non-conservative Federal and NSW State governments (lowest RR) through conservative Federal and non-conservative NSW State governments (and vice versa), to conservative Federal and NSW State governments.

These findings do not seem to be artefactual given that the models controlled for identified ecological risk factors for suicide. Importantly, a consistent dose-response relation emerged. The models correctly identified known factors associated with suicide rate changes, particularly the artefactual decrease in male suicide during the second world war and the increase in female suicide during the 1960s sedative epidemic. The positive association between suicide risk and conservative governments also remained after analyses excluded the periods where conservative and Labor governments coincided with observed suicide increases and decreases known to be associated with other factors. The positive association between conservative governments and increased suicide risk was also evident when pre-second world war and post-second world war periods were examined separately, and when age specific analyses were carried out. In short, the trend of increasing suicide risk from Labor to conservative government categories remained after adjusting for identified ecological confounding.

This study investigates the association between suicide in NSW and Federal and NSW State political regimes over an extended period in terms of their broad ideological underpinnings. Previous investigations of suicidal behaviour and politics have focused on the possible association with general elections in the United States and United Kingdom, ${ }^{30-32}$ and also the association of a single significant sociopolitical event with suicide. ${ }^{33-37}$ Masterton and Platt ${ }^{30}$ investigated parasuicide over a 20 year period in Scotland in relation to general election results, and found increased incidence of parasuicide in the period after Conservative electoral victories but not Labour electoral victories. No association between suicide and presidential elections in the United States has been found. ${ }^{31}{ }^{32}$ Of more relevance to the current findings are a series of studies investigating suicide in the former Soviet Union. ${ }^{33-37}$ Changes to the political regime during the period of perestroika between 1984-1990 saw significant decreases in the suicide rate ( $32 \%$ and $18 \%$ for men and women respectively). These decreases have been attributed in part to democratic political reforms coupled with a sense of optimism and hope of improved living conditions, but also coincided with a strict anti-alcohol policy. ${ }^{35}$ Since then, when illusions in the "magic of the market" were destroyed, suicide rates in the former Soviet Union and Eastern Europe increased again and remain the highest in the world..$^{47}$

The results of this study suggest that government programmes or perceived prospects under particular governments may be influential to some extent despite broader economic and historical trends that may also be associated with population suicide rates. For example, decreases in GDP are associated with increased male suicide, but increases in GDP were not as strongly associated with commensurate decreases in male suicide.

The effect of the political variables may indicate the more subtle influences of political programmes on wider socioeconomic trends, but could also be bound up in the inherent autoregressive process of what is a relatively long time series

\section{Key points}

- Conservative governments at both NSW (State) and Federal level associated with significantly higher suicide rates.

- Significant suicide risk dose-response relation with NSWFederal governments, from both Labor (lowest), to mixed (middle), to both Conservative (highest).

- Differences underpinning conservative and social democratic government programmes discussed in terms of Durkheim's notion of "anomie".

of suicide rates. Interrupted time series analysis revealed that the effect of government type was positively associated with suicide in men and women, but this was statistically non-significant. However, while the positive association between suicide and the 1960s sedative epidemic was found to be significant in time series analysis of female suicide by poisoning only, the negative association between suicide and the large artefactual decrease during the second world war in male suicide was found to be non-significant despite the association being in the hypothesised direction. Given that both these large effects have been documented as robust, the problem may lie in correctly specifying the onset of the intervention as it actually occurred when conducting time series analysis. While the second world war can be clearly delineated as a "step function" intervention, its actual operation on suicide rates was more gradual in that increasing and then decreasing proportions of the male population were drafted into the armed forces during the course of the seond world war. While this example illustrates the inherent difficulty in correctly specifying a hypothesised mechanism of intervention (and hence its "shape"), this is simple compared with characterising the mechanics of an "intervention" due to a political regime. The introduction of different major social programmes would need to be assessed in their impact on some population characteristic and correlated with annual suicide data. While such characterisation is beyond the scope of this paper, it would be of interest to examine the correlation of a well characterised social programme intervention with suicide rates.

The positive association between drought occurrence and suicide may be more a reflection of the impact of the announcement of drought itself, and can perhaps more appropriately be conceptualised as a step function. Other climatological variables such as seasonality, precipitation and temperature, potential confounders not included in this study, may also reveal more subtle interactions between secular trends in these variables and suicide rates. However, seasonal variation in suicide occurs within a year, while suicide data over long periods are available only on an annual basis, precluding seasonal analysis.

The relation between suicide rates and political regime is reported here because of the agreement in the magnitude and direction of effects in both Poisson regression and time series analysis despite this not attaining statistical significance in time series analysis when regime was specified as a simple step function. That is, there seems to be evidence of an effect on suicide rates attributable to political regime in NSW and Australia but sufficiently characterising the form of the intervention for more rigorous analysis is not yet possible.

In Australia the ideological distinction between conservative and Labor politics historically has not been extensive and has decreased over the past two decades. Yet the differences in programme formulation and implementation in practice nevertheless may make a difference to people's perceived prospects. Conservative ideology traditionally is less interventionist and more market orientated than that of a social democratic ideology. From a Durkheimian perspective, increased anomie (decreased connectedness or inclusiveness), is 
thereby more strongly associated with conservative ideology. Such ideological differences may be reflected in social programmes implemented, with Labor governments traditionally implementing more regulatory programmes pertaining to, for example, employment, health, and education. ${ }^{48}$ This was made easier in the second half of the century by constitutional changes made under the Chifley government, which enabled greater Federal intervention in areas such as social services. ${ }^{49}$ Conservative government programmes reflect more a willingness to subsidise existing private sector services (for example, health, education, employment) than extend the responsibilities of the state. ${ }^{50}$ Revived, particularly in the post-second world war era, has been the "rhetoric of individualism (the Victorian virtues of self help and thrift, to which might well be added the other three, abstinence, piety and respectability)" ${ }^{48}$

Given the ecological nature of this study, other intermediary variables not included such as individual (for example, mental illness) and interpersonal (for example, degree of isolation) factors, may further explain the relation between suicide rates and political regimes. However, population prevalences of intermediary variables between broad social indicators and the individual decision to commit suicide generally are not known, and certainly not known over any significant time span. Where such individual data are available multilevel statistical models that adjust for the "random" and "fixed" effects of individual or interpersonal factors are the most appropriate method (factors such as age and individual SES nested within broader social determinants such as area based SES). ${ }^{51}{ }^{52}$ This study included only age and sex as "individual" level variables, with suicide and population data aggregated to five year age groups included in separate models by sex largely to adjust for differential age effects over time. Cross level (ecological) bias can arise as a consequence of effect modification or covariate misspecification, particularly in mixed models that infer individual level characteristics from group level characteristics and vice versa. ${ }^{53}{ }^{54}$ However, the current analyses are "unmixed" in nature ${ }^{54}$ and are interpreted in the context of population level characteristics. Although there may have been characteristics of periods associated with political tenure that are determinants of suicide not adjusted for in the models (unmeasured confounders), the replication of results at Federal and State levels, and the dose-response demonstrated, suggest a true association of suicide with political tenure.

At an individual level, personal factors will overwhelmingly influence an individual decision to commit suicide. Personal factors such as a history of mental illness, ${ }^{55}$ previous suicide attempts, ${ }^{565}$ feelings of hopelessness and aggression, ${ }^{57}{ }^{58}$ and familial and/or marital discord ${ }^{59}$ have all been shown to be significantly associated with a higher risk of suicide or attempted suicide. Such factors will contribute to the likelihood of a suicide, but the context for these individual influences and risk factors cannot be ignored either. If social factors can interact with and mediate biological and cognitive substrates of individual behaviour, then they can act independently as determinants of health and wellbeing. ${ }^{60}$ Under favourable social and economic conditions an individual with risk factors for suicide is less likely to decide to commit suicide than under conditions where life prospects are bleak or uncertain. This is because an individual suicide is the result of a decision to do so, which in turn is the outcome of a cognitive process, as impaired as it might be, in which life's prospects are a major part of the decision equation. If life is not worth living it is because there is nothing to live for. This notion is also supported by studies of attempted suicide in which depression on its own has been found to be a poor predictor of suicide, as has hopelessness, but depression and hopelessness together were found to be significantly predictive of suicidal behaviour. ${ }^{61-63}$ That is, if hopelessness is a necessary but not sufficient condition for suicide, then regimes that offer less hope to the bulk of the population will also increase the probability of suicide in groups that have pre-existing or newly acquired risk factors for suicide.

\section{Authors' affiliations}

A Page, S Morrell, R Taylor, School of Public Health, University of Sydney, Australia

\section{REFERENCES}

1 Durkheim E. Suicide: a study in sociology. New York: The Free Press, 1979.

2 Morrell S, Taylor R, Quine S, et al. Suicide and unemployment in Australia 1907-1990. Soc Sci Med 1993;36:749-56.

3 Gunnell D, Lopatatzidis A, Dorling D, et al. Suicide and unemployment in young people. Analysis of trends in England and Wales, 1921-1995. BrJ Psychiatry 1999; 175:263-70.

4 Leenaars AA, Lester D. The changing suicide pattern in Canadian adolescents and youth, compared to their American counterparts. Adolescence 1995;30:539-47.

5 Hintikka J, Saarinen PI, Viinamaki H. Suicide mortality in Finland during an economic cycle, 1985-1995. Scand J Public Health 1999;27:85-8.

6 Weyerer S, Wiedenmann A. Economic factors and the rates of suicide in Germany between 1881 and 1989. Psychol Rep 1995;76:1331-41.

7 Lester D. Economic factors and suicide. J Soc Psychol 1988; 128:245-8

8 Oliver RG, Hetzel BS. Rise and fall of suicide rates in Australia: relation to sedative availability. Med J Aust 1972;2:919-23.

9 Surtees PG, Duffy JC. Suicide in England and Wales 1946-1985: an age-period-cohort analysis. Acta Psychiatr Scand 1989;79:216-23.

10 Kreitman N. The coal gas story. United Kingdom suicide rates, 1960-71. Br J Prev Soc Med 1976;30:86-93

11 Cantor $\mathbf{C H}$, Baume PJ. Access to methods of suicide: what impact? Aust N Z J Psychiatry 1998;32:8-14.

12 Cantor $\mathrm{CH}$, Slater PJ. The impact of firearm control legislation on suicide in Queensland: preliminary findings. Med J Aust 1995;162:583-5.

13 Preti A, Miotto P. Seasonality in suicides: the influence of suicide method, gender and age on suicide distribution in Italy. Psychiatry Res 1998:81:219-31.

14 Lester D, Frank ML. Geophysical variables and behavior: LIX. The seasonal variation in suicide rates: three studies. Percept Mot Skills 1990;70:57-8.

15 Yip PS, Chao A, Ho TP. A re-examination of seasonal variation in suicides in Australia and New Zealand. J Affect Disord 1998:47:141-50.

16 Preti A. The influence of seasonal change on suicidal behaviour in Italy. J Affect Disord 1997;44:123-30.

17 Maes M, De Meyer F, Thompson P, et al. Synchronised annual rhythms in violent suicide rate, ambient temperature and the light-dark span. Acta Psychiatr Scand 1994;90:391-6.

18 Souetre $E$, Wehr T, Douillet $P$, et al. Influence of environmental factors on suicidal behavior. Psychiatry Res 1990;32:253-63.

19 Salib E, Gray N. Weather conditions and fatal self-harm in North Cheshire 1989-1993. Br J Psychiatry 1997:171:473-7.

20 Kaasik T, Andersson R, Horte LG. The effects of political and economic transitions on health and safety in Estonia: an Estonian-Swedish comparative study. Soc Sci Med 1998;47:1589-99.

21 Watson P. Health difference in eastern Europe: preliminary findings from the Nowa Huta study. Soc Sci Med 1998;46:549-58.

22 Cereseto S, Waitzkin H. Economic development, political-economic system, and the physical quality of life. Am J Public Health 1986;76:661-6.

23 Cereseto S, Waitzkin H. Capitalism, socialism, and the physical quality of life. Int J Health Serv 1986:16:643-58.

24 Quine S, Taylor R, Hayes L. Australian trends in mortality by socioeconomic status using NSW small area data, 1970-89. J Biosoc Sci 1995;27:409-19

25 Taylor R, Quine S, Lyle D, et al. Socioeconomic correlates of mortality and hospital morbidity differentials by Local Government Area in Sydney 1985-1988. Aust J Public Health 1992;16:305-14.

26 Davey Smith G, Dorling D. "I'm all right, John": voting patterns and mortality in England and Wales, 1981-92. BMJ 1996:313:1573-7.

27 Kondrichin SV, Lester D. "I'm all right Jack" in Russia too. Percept Mot Skills 1999:88:892.

28 Carlson E, Tsvetarsky S. Birthweight and infant mortality in Bulgaria's transition crisis. Paediatr Perinat Epidemiol 2000;14:159-62.

29 Lena HF, London B. The political and economic determinants of health outcomes: a cross-national analysis. Int J Health Serv 1993;23:585-602.

30 Masterton G, Platt S. Parasuicide and general elections. BM 1989;298:803-4

31 Lester D. Suicide and presidential elections in the USA. Psychol Rep 1990;67:218.

32 Lester D. Suicide and homicide rates during Presidential terms as a function of economic conditions. Psychol Rep 1993;73:50. 
33 Varnik A, Wasserman D, Dankowicz $M$, et al. Age-specific suicide rates in the Slavic and Baltic regions of the former USSR during perestroika, in comparison with 22 European countries. Acta Psychiatr Scand Suppl 1998;394:20-5

34 Varnik A, Wasserman D, Dankowicz M, et al. Marked decrease in suicide among men and women in the former USSR during perestroika. Acta Psychiatr Scand Suppl 1998;394:13-19.

35 Wasserman D, Varnik A. Suicide-preventive effects of perestroika in the former USSR: the role of alcohol restriction. Acta Psychiatr Scand Suppl 1998;394:1-4

36 Wasserman D, Varnik A, Dankowicz M. Regional differences in the distribution of suicide in the former Soviet Union during perestroika, 1984-1990. Acta Psychiatr Scand Suppl 1998:394:5-12.

37 Wasserman D, Varnik A, Eklund G. Female suicides and alcohol consumption during perestroika in the former USSR. Acta Psychiatr Scand Suppl 1998;394:26-33

38 Jaensch D. Power politics: Australia's Party system. Sydney: Allen and Unwin, 1983

39 Cantor C, Neulinger K. The epidemiology of suicide and attempted suicide among young Australians. Aust N Z J Psychiatry 2000;34:370-87.

40 Hassan R. Suicide explained: the Australian experience. Melbourne: Melbourne University Press, 1995

41 Butlin NG. Australian national accounts, 1788-1983. Canberra: Australian National University, 1985

42 Bureau of Meteorology. Living with drought. Canberra: Commonwealth Government of Australia, 1997.

43 Taylor R, Lewis M, Powles J. The Australian mortality decline: all-cause mortality 1788-1990. Aust N Z J Public Health 1998;22:27-36

44 Grattan M, ed. Australian Prime Ministers. Frenchs Forest: New Holland, 2000

45 New South Wales Parliamentary Library. Premiers, leaders of the opposition, and whips in the Parliament of New South Wales, 1901-1979: a checklist. Sydney: Library of New South Wales Parliament, 1980

46 SAS. Statistical software. Version 6.12. Cary, NC: SAS Institute, 1996.

47 World Health Organisation. Figures and facts about suicide. Geneva: World Health Organisation, 1999.
48 Roe J, ed. Social policy in Australia: Some perspectives 1901-1975. Stanmore: Cassell Australia, 1976.

49 Clark CMH. A history of Australia. Carlton: Melbourne University Press, 1962.

50 Kewley TH. Social security in Australia, 1970-1972. Sydney: Sydney University Press, 1973.

51 Bullen N, Jones K, Duncan C. Modelling complexity: Analysing between-individual and between-place variation - a multilevel tutorial Environment and Planning A 1997;29:589-609.

52 Subramanian SV, Kawachi I, Kennedy BP. Does the state you live in make a difference? Multilevel analysis of self-rated health in the US. Soc Sci Med 2001;53:9-19.

53 Piantadosi S. Invited commentary: ecologic biases. Am J Epidemiol. 1994;139:761-4

54 Susser M. The logic in ecological: I. The logic of analysis. Am J Public Health 1994:84:825-9.

55 Moscicki EK. Epidemiology of suicidal behavior. Suicide Life Threat Behav 1995;25:22-35

56 Diekstra RF. The prevention of suicidal behavior: evidence for the efficacy of clinical and community-based programs. International Journal of Mental Health 1992;21:69-87.

57 Beck AT, Brown G, Berchick RJ, et al. Relationship between hopelessness and ultimate suicide: a replication with psychiatric outpatients. Am J Psychiatry 1990;147:190-5

58 Brent DA, Johnson B, Bartle S, et al. Personality disorder, tendency to impulsive violence, and suicidal behavior in adolescents. J Am Acad Child Adolesc Psychiatry 1993;32:69-75.

59 Beautrais AL, Joyce PR, Mulder RT. Risk factors for serious suicide attempts among youths aged 13 through 24 years. J Am Acad Child Adolesc Psychiatry 1996;35: 1 174-82.

60 Shenassa ED. Society, physical health and modern epidemiology. Epidemiology. 2001;12:467-70.

61 Lester D. Helplessness, hopelessness, and haplessness and suicidality. Psychol Rep 1998;82:946

62 Dyer JA, Kreitman N. Hopelessness, depression and suicidal intent in parasuicide. Br J Psychiatry 1984;144:127-33

63 Beck AT, Steer RA, Kovacs M, et al. Hopelessness and eventual suicide: a 10-year prospective study of patients hospitalized with suicidal ideation. Am J Psychiatry 1985;142:559-63.

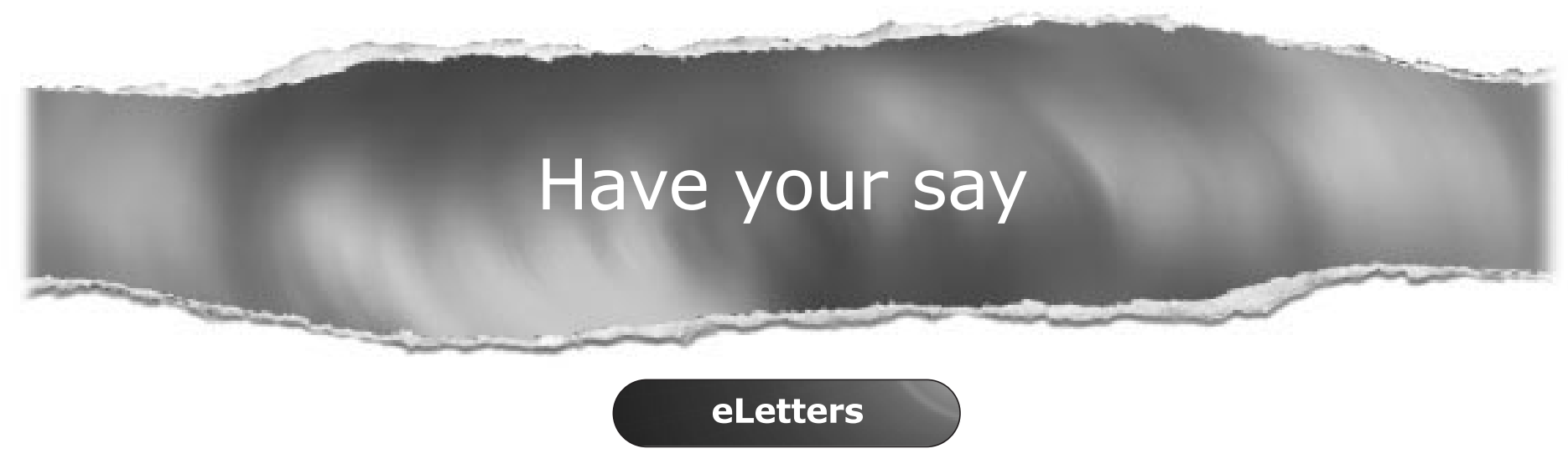

If you wish to comment on any article published in the Journal of Epidemiology and Community Health you can send an eLetter using the eLetters link at the beginning of each article. Your response will be posted on Journal of Epidemiology and Community Health online within a few days of receipt (subject to editorial screening).

\section{www.jech.com}


LETTERS

If you have a burning desire to respond to a paper published in JECH, why not make use of our "rapid response" option?

Log on to our web site (www.jech.com), find the paper that interests you, and send your response via email by clicking on the "eletters" option in the box at the top right hand corner.

Providing it isn't libellous or obscene, it will be posted within seven days. You can retrieve it by clicking on "read eletters" on our homepage. The editors will decide as before whether to also publish it in a future paper issue.

\section{The connection between milk and mortality from coronary heart disease}

May I join the debate between Drs Ness ${ }^{1}$ and Segall ${ }^{2}$ on the above subject?

The suspicion that excessive milk consumption was associated with increased coronary mortality arose in the 1950s when it was customary to treat peptic ulcer with large quantities of milk. The practice was discontinued when it was found that many of the so treated patients died of coronary heart disease. Extensive investigations at the time in American and British hospitals seem to have confirmed the suspicion.

Naturally, it would be interesting to see whether in the long run the consumption of non-excessive quantities of milk was also connected with heart disease. One method of finding out, as Ness and colleague have done, is to recruit a number of volunteers, establish their milk consumption and wait 20 years to see whether the high consumer fared worse than he low consumers.

Apart from the long wait a disadvantage is that a significant part of milk consumption is hidden in milk products, like chocolate, ice cream, etc, tends to be discounted and make the results unreliable.

An alternative method is to take advantage of the fact that developed countries have published both mortality and food consumption statistics for the best part of the century. It is, therefore, possible to correlate coronary mortality in various countries with their very different average milk consumption.

I carried out several such studies in the $1980 \mathrm{~s}^{3}$ invariably showing a strong correlation between them.

Statistical studies also produce evidence regarding the critical constituent of milk. There is no connection between fermented milk products, like cheese, and coronary disease. When milk is fermented, milk sugar, lactose, is converted into lactic acid, strongly in favour of Dr Segall's discovery of the crucial importance of lactose.
Statistical studies also show another important variable, climate. Mortality is high in cold countries, like Russia and its neighbours, very low in the tropics.

This calls attention to another component of milk, calcium, sweat glands being an important calcium excretor. In cold climates the amount of calcium excreted by sweating is small, in the tropics it can be several times the quantity excreted by the kidneys.

A little appreciated biological fact is that the calcium requirements of the body vary greatly in various age groups. Ninety nine per cent of the calcium content of the body is in the skeleton and teeth, which reach their full size by the age of 32. Nature's solution of this problem is to make the walls of the intestines impenetrable for calcium. A special substance, 1,25 dihydroxy-cholecalciferol, is needed to transfer calcium through the intestines. For the other extreme case, when the calcification of the infant skeleton needs comparatively large quantities of calcium, nature produced a special nutrient, milk. Milk is not only high in calcium, but milk sugar, lactose, assists in its transfer through the intestinal wall, essentially the same way as cholecalciferol.

The human habit of consuming the milk of another species as food for all age groups invalidates the natural expedient for ensuring calcium intake according to needs. The lactose of cow's milk causes the absorption of its calcium content whether it is needed or not. Briefly, the intake of excess calcium in old age results in the hardening of the arteries, hence its connection with mortality from coronary heart disease.

\section{S Seely \\ 3 Truro Drive, Sale, Cheshire M33 5DF, UK}

\section{References}

1 Ness AR, Davey Smith G, Hart C. Milk, coronary heart disease and mortality. J' Epidemiol Community Health 2001;55:379-82.

2 Segall JJ. Milk and coronary heart disease mortality. J Epidemiol Community Health 2002;56:319

3 Seely S. Diet and coronary arterial disease: a statistical study. Int J Cardiol

1988;20:180-92.

\section{Marital confusion}

As someone divorced, married, separated, and cohabiting and who is constantly frustrated at trying to fill in my status on forms, I welcome the recent attempt to sort out the confusion about marital status among questionnaire compilers. ${ }^{1}$ However, I think the layout shown in figure $\mathrm{l}$ is simpler than their final version 3 (for heterosexual women) while providing more information, redundancy (and reliability).

A G Gordon

32 Love Walk, London SE5 8AD, UK

\section{Reference}

1 Barret G, Wellings K. Collecting information on marital status: a methodological note. $J$ Epidemiol Community Health 2002;56:175-6.
Who(m) do you live with?

Tick all boxes that apply now

Children

Husband

Partner

Your parent(s)

His parent(s)

Other relatives, friends

Others

None of these

What is your current marital status?

Tick all that apply now
Married
Remarried
Partnered
Separated
Divorced
Widowed
None of these

What was your previous marital status? Tick all that used to apply, but not now

Married
Partnered (not husband) $\square$
Divorced
Widowed
None of these

Figure 1 Version 4

\section{Author's reply}

We are very glad that our paper has stimulated interest in this topic. The point of our paper was that we found current questions on marital/partnership status to be misunderstood and unacceptable to many women; the three versions presented in the paper were intended to illustrate the difficulties we encountered in seeking a solution. Developing questions that are reliable, concise, and valid in lay terms is not an easy task, and our experience underlines the importance of testing new questions for their comprehensibility and acceptability.

G Barrett

Health Promotion Research Unit, Department of Public Health and Policy, London School of Hygiene and Tropical Medicine, Keppel Street, London WCIE 7HT, UK; geraldine.barrett@Ishtm.ac.uk

\section{BOOK REVIEWS}

On fairness and efficiency. The privatisation of the public income over the past millennium

G Miller. The Policy Press, 2000. (Pp 470; no price stated). ISBN 1-86134-221-7

Starting out from the economic hypothesis advanced by Henry George in the 1880s-that is, the distorted balance between land, capital and labour, or rent, benefit and wages, this 
book seeks to explain all the contradictory features of the welfare capitalism period. The author places himself within a long tradition of "political medicine" that contributes to our understanding of society from the rationality of health. The issue tackled is: How does our social context affect human lives in terms of quality and duration of life? If epidemiology is able to provide definite knowledge about the second half of this question, as it does in the first part of this book, a great deal of scholarship and the predilection for history and sharp sociological insight shown by this author are required to continue explaining the "context" through the abridged social history of Britain in the second and last part of the book. Miller's thorough examination of the British welfare state includes an evaluation of inequalities in death and morbidity and of the effects of unemployment on citizens' health, as well as an analysis of welfare measures (such as education, healthcare schemes, social insurances, and housing). The overall conclusion is that welfare politics have historically been unable to reduce the gap of health inequality. It is not the general aims of welfare state that are discussed, but their extreme inadequacy. The author claims that George's theories (which favour a "single tax" economic foundation for the State) have not been intellectually defeated but are repressed solely by political will in a political landscape dominated by the "lords of the rent", who are primarily "lords of the land". If, at the outset of the 21 st century, we are rightly entitled to regard any single cause social theory with suspicion, the hard epidemiological facts stand as testimony for the prosecution of "the deadly legacy" imposed by social inequities. Certainly, Miller's proposition that the offer of "help in lieu of entitlement" lies at the heart of the inadequacy of welfare politics is worthy of serious further consideration.

E Rodríguez Ocaña Department of History of Medicine, University of Granada, Spain

\section{Traditional family values and substance abuse}

$M$ Cuadrado, L Lieberman. Kluwer Academic Press, 2002.

From the authors' point of view the book examines the proposition that the differences found in substance use and misuse behaviour among Puerto Ricans living in the United States are based on adherence to a strong identity to Puerto Rican tradition. The traditional values taken into account in this volume are essentially family values; that is, the values that help define the role of husband and wife toward each other and the raising of children on a day to day basis. So they are gender based values. The authors think the relationships between tradition, family, and values have general common threads running through all societies, but need to be understood separately for each group. The final aim is to have an empirical base for a culturally appropriate use of ethnotherapy in persons with drug or alcohol problems.

The content is more modest: a cross sectional survey of drinking behaviour and substance use and norms among the Puerto Rican population living in the New York metropolitan area. The results of the impact of high and low acculturation and high and low traditionalism on outcome variables and the differences between men and women are interesting and not surprising knowing the cultural norms and beliefs of the Hispanic tradition. Nevertheless, far from the authors' objectives, the results of the study confirm that, as in any other culture, these norms are sometimes relevant high risk factors for the development of drinking or drug using problems, although in other cases they behave as protective factors. Finally, the authors place a more modest role for ethothearapy "ethnotherapy with Hispanics is merely a suggestion for creating a therapeutic and accepting environment in which Hispanics substance abusers can raise their levels of traditionalism and ethnic identity as a foundation for dealing with their substance abuse".

L de la Fuente

Centro Nacional de Epidemiología, Instituto de Salud Carlos III, Madrid, Spain

\section{Epidemiology. An introduction}

K J Rothman. Oxford University Press, 2002. (Pp 223; price not stated). ISBN: 0-19513553-9 (hardback); 0-19-5 $13554-7$ (paperback).

The aim of this book is clearly stated by $\mathrm{K} \mathrm{J}$ Rothman in the preface: “... to present a simple overview of the concepts that are the underpinnings of epidemiology, so that a coherent picture of epidemiology thinking emerges for the student. The emphasis is not on statistics, formulas, or computation, but on epidemiologic principles and concepts". In fact, this is the essence of the book: conceptual, simple, and introductory to the epidemiological logic. It has been conceived as an introductory text to a general course in epidemiology.

The book is structured into 11 chapters. Chapter 1 is an introduction to epidemiological thinking, based on the concept of confounding that "illustrates that epidemiology is more than just common sense". Chapters 2 to 4 deal with the topics of causation, measuring disease ocurrence and causal effects, and types of epidemiological studies. Chapters 5 and 6 deal with measurement error (biases and random error). Chapters 7 to 10 are devoted to the methods for analysing epidemiological effects, including an introduction to some more advanced issues, as controlling of confounding by stratifying data, measuring interactions, and using regression models in epidemiological analysis. Finally, chapter 11 deals with clinical epidemiology, including some concepts related to diagnosis and clinical trials.

The book has successfully met its pedagogical goal. Main epidemiological concepts and principles are presented in a simple language, as if they were being explained in a classroom, illustrated with clear and attractive examples, and all chapters contain a set of questions for further study. Moreover, a web site that supports reader participation and provides answers to these questions is available (http:// www.oup-usa.org/epi/rothman).

Though the aim of the author was to write a basic text, he also introduces the principles for more advanced issues, establishing the basics for understanding interaction and multivariable regression models.

S Márquez-Calderón Andalusian School of Public Health, Granada,

Spain

\section{Making sense of data}

J H Abramson, Z H Abramson. Oxford University Press, 2001. (Pp 384; $£ 50.00$ (hardback), £29.50 (paperback). ISBN (hardback) 0-19-514524-0; (paperback): 0-19$514525-9$

This is a book for learning epidemiology. It is oriented to understand what data tell us (and what data do not tell us). It seems that the authors' intentions are directed to change the way of thinking, in order to adequately comprehend scientific approaches to public health issues and to develop a critical mind. This is especially important in the first steps taken in this field because basic concepts are easy but minds are not naturally qualified for appraising certain types of (abstract) problems. But for this training a personal effort is unavoidable and authors make it explicit by emphasising that it is a workbook. But the investment is worthwhile.

The book is structured in sections containing short exercises, comments on previous questions, and explanatory text. Each section ends with a self test. The seven sections are adequately ordered (this is not trivial) and cover all the relevant issues of most textbooks of epidemiology. The book goes beyond the introductory level; it includes stratification and concepts on the interpretation of multivariate methods most commonly used in epidemiological studies, like logistic regression and proportional hazards models. One section deals with meta-analysis and the last one covers important and complex aspects related to what to do with the findings of epidemiological studies, with published data, information from the media, etc, before a decision is to be made.

Making sense of data is an excellent book. It is perfect for those determined to learn epidemiology and also for those determined to teach epidemiology and are comfortable with the proposed orientation. I would like to underline the authors' suggestion that working in collaboration with others will be helpful in some cases. Although it is not practical as a textbook (authors recognise this) because of its structure, there is no doubt that thoughtful, sound concepts and methods are in there.

J Damián

National Centre for Epidemiology and National School of Public Health, Instituto de Salud Carlos III,

Madrid

\section{Computer programs for epidemiologists. PEPI v. 4.0}

J H Abramson, P M Gahlinger. (Pp 305; \$59.95). Salt Lake City: Sagebrush Press, 2001. ISBN 0-9703130-2-0

The book is the manual of PEPI version 4.0, a collection of programs that includes a variety of programs for use in statistical analysis and planning of epidemiological studies, covering sample size estimation, contingency tables, standardisation, logistic regression, survival analysis-although no Cox regression-, 
smoothing of curves, and much more Each program offers a number of options and outputs (the authors claim that "The programs may offer more options than you need, and most will display more results that you need"); this enlarges the range of possible users. The manual is clearly written and provides the main uses of each program as well as some mathematical details.

Logistic regression programs read data files. All the other programs work on elaborated data (for example: rates or number of observations in each cell of a table); therefore primary data must be tabulated or counted using other statistical software before using PEPI, and then elaborated data must be entered at the keyboard.

Users of statistical packages (such as Stata, SPSS, or SAS) can find PEPI rather tedious because of this two phase procedure (tabulation in another program, analysis in PEPI) Furthermore, many programs in PEPI require reinitialisation each time you want to introduce new data. Nevertheless, my initial scepticism was modified after using it: when I needed to estimate the sample size for a matched case-control study, I could compare several packages and found that PEPI provides an output richer than others do. This feature is common to other programs in PEPI they cover a variety of epidemiological tests wider than general purpose statistical packages.

Epidemiologists can use PEPI with two main purposes when analysing data: as an alternative to statistical programs that are more expensive, or as a complementary toolbox when other programs are available. Teaching and learning purposes are also possible.

J Llorca

Division of Preventive Medicine and Public Health University of Cantabria School of Medicine Santander, Spain

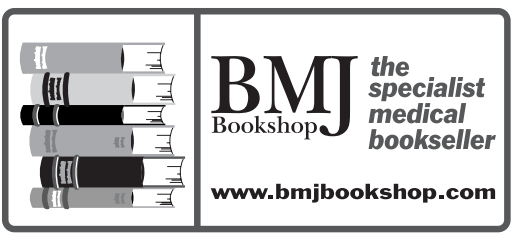

\section{CORRECTION}

An editorial error occurred in the paper by Dr A Page and colleagues (2002;56:766-72). Both the male and female suicide rates in each category of the Gross Domestic Product variable (tables 1, 2, and 3) are not correct. The correct male and female suicide rates by GDP change category are shown in the accompanying data. These minor numerical translocations do not affect the analysis, results, or conclusions in any way.

\begin{tabular}{|c|c|c|}
\hline \multicolumn{3}{|c|}{ Corrected data for GDP variable } \\
\hline \multicolumn{3}{|c|}{ Age adjusted suicide rates per 100000 : } \\
\hline & Men & Women \\
\hline \multicolumn{3}{|l|}{$\begin{array}{l}\% \text { Annual change in } \\
\text { GDP }\end{array}$} \\
\hline Minus $10 \%$ & 34.47 & 7.32 \\
\hline Minus 5-9\% & 26.81 & 6.74 \\
\hline Minus $4 \%$ to plus $4 \%$ & 23.94 & 7.25 \\
\hline Plus $5-9 \%$ & 25.62 & 8.48 \\
\hline Plus $10 \%$ & 23.94 & 8.77 \\
\hline
\end{tabular}

